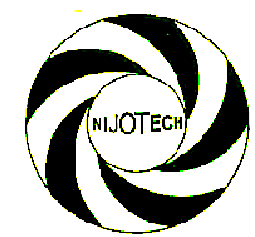

Nigerian Journal of Technology (NIJOTECH)

Vol. 33 No. 4, October 2014, pp. 442 - 446

Copyright@ Faculty of Engineering,

University of Nigeria, Nsukka, ISSN: $1115-8443$ www.nijotech.com

http://dx.doi.org/10.4314/nit.v33i4.4

\title{
EVALUATING PERFORMANCES OF TRAFFIC NOISE MODELS
}

\author{
0. J. Oyedepo

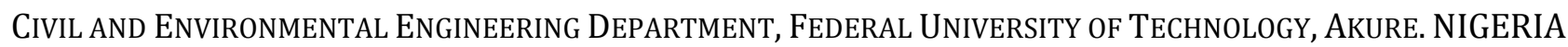 \\ E-mail address: oyedepoo@yahoo.co.uk
}

\begin{abstract}
Traffic noise in decibel $d B(A)$ were measured at six locations using 407780A Integrating Sound Level Meter, while spot speed and traffic volume were collected with cine-camera. The predicted sound exposure level (SEL) waS evaluated using Burgess, British and FWHA model. The average noise level obtained are $77.64 \mathrm{~dB}(\mathrm{~A}), 72.95$ $d B(A)$ and $75 d B(A)$ respectively; The values from Burgess and FWHA model lies within an error band of $\pm 5 \%$ with reference to the observed noise levels. Thus, the three models are effective in predicting equivalent traffic noise index in Akure with fair accuracy. The coefficient of correlation $\left(R^{2}\right)$ between observed sound exposure level and predicted sound exposure level are 0.931 and 0.968 respectively; thus, there is a good correlation between the observed and the predicted value. Adequate road design and management of traffic flow are recommended to reduce road traffic noise in the study area.
\end{abstract}

\section{Keywords: Transportation, Traffic volume, Noise, Road, Management}

\section{INTRODUCTION}

Noise is unacceptable level of sound that creates annoyance, hampers mental and physical peace, and may induce severe damage to the health. Transportation operations are major contribution to noise in the modern urban environment; traffic noise is generated by the engine and exhaust systems of vehicle, by aerodynamics friction and by the interaction between vehicles and its support system (e.g., tyre-pavement and rail wheel-rail interactions). Road traffic noise, thus, is a very important element in environmental impact studies, since car is one of the most used transportation mean in developing countries like Nigeria. It is one of the harmful agents for citizenships; therefore many countries have introduced noise emission limits for vehicles and other legislations to reduce road traffic noise $[1,9,13$, 15].

Noise levels are showing an alarming rise and it exceeds the prescribed levels in most of the urban cities of developing countries like Nigeria and Akure in particular. Noise in big cities is considered by the World Health Organization (WHO) to be the third most hazardous type of pollution, right after air and water pollution [16]. Investigation in several countries in the past decades has shown that noise has adverse effect on human health, living in close proximity to busy road highways $[12,3,7,8,14,4$, and 10]. Table 1 show the different standards of noise Level for various areas of a community. However, the recognition of traffic noise as one of the main sources of environmental pollution has led to the development of mathematical models that enable the prediction of traffic noise level from fundamental variables such as the flow and velocity of vehicles among others. Traffic noise prediction models are commonly needed to predict sound pressure levels, specified in terms of $\mathrm{L}_{\text {Aeq, }} \mathrm{L}_{10}$, etc. The models are also required as aids in design of roads and sometimes in assessment of existing, or envisaged changes in traffic noise conditions. Some of the traffic noise models that were designed to analyze the impact of noise in an environment are:

\section{(a) Burgess Model (1977):}

$$
\text { LAeq }=55.5+10.2 \log Q+0.3 p-19.3 \log (L / 2)
$$

In (1), $p$ is the percentage of heavy vehicles, $L$ is the road width in metre and $Q$ is the total number of vehicles per hour

$$
\begin{aligned}
& \text { (b) Acoustic Society of Japan (ASJ) Model (1998): } \\
& L A_{\text {eq }}(\text { without building })=10 \log 10\left(10^{\frac{L A E}{10}} \times \frac{N}{t}\right)
\end{aligned}
$$


In (2), $\mathrm{N}$ is traffic volume (vehicles/ second), and $\mathrm{t}$ is time interval in seconds.

(c) British Standard-5228 (2009):

$$
\begin{aligned}
L_{A e q}=L_{W A}- & 3 \\
& +10 \log _{10} Q \\
& -10 \log _{10} V-10 \log _{10} d(3)
\end{aligned}
$$

In (3), LWA is the sound power level of the plant in decibel $(\mathrm{dB})$; $\mathrm{Q}$ is the number of vehicle per hour; $\mathrm{V}$ is the average vehicle speed, in $\mathrm{m} / \mathrm{sec}$ and $\mathrm{d}$ is the distance of the receiving position from the center of the haul road in metre $(\mathrm{m})$. (d) Federal Highway Administration Standard (FHWA) Model (2002):

$$
\begin{aligned}
L A_{e q}=10 \log 10 & \left\{( \frac { 1 } { T } ) ( \frac { N } { 1 0 0 } ) \left(P \times 10^{\frac{S E L}{d}}\right.\right. \\
+ & \left.\left.\left.(100-P) \times 10^{\frac{S E L}{d}}\right)\right)\right\}
\end{aligned}
$$

In (4), $\mathrm{N}$ is the total vehicle flow in the time period $\mathrm{T}(\mathrm{s})$; $\mathrm{T}$ is time in sec., $\mathrm{p}$ is the percentage of heavy vehicles and $d$ is the distance of receiving position in

\begin{tabular}{|c|c|c|c|c|c|}
\hline \multirow[b]{2}{*}{ S/No } & \multirow[b]{2}{*}{ Description of Area } & \multicolumn{4}{|c|}{ Noise Level dB(A) } \\
\hline & & $\begin{array}{l}\text { Day time }(6: 00 \\
\text { am -9:00 pm) }\end{array}$ & $\begin{array}{c}\text { Night time } \\
(9: 00 \mathrm{pm}-6: 00 \\
\mathrm{pm})\end{array}$ & FHWA & AASHTO \\
\hline 1. & $\begin{array}{l}\text { Sensitive Areas such as } \\
\text { parks, schools, hospital, } \\
\text { mosques and silence } \\
\text { area }\end{array}$ & 50 & 40 & 60 & $55-60$ \\
\hline 2. & Residential Area & 55 & 45 & $\begin{array}{l}70 \text { Exterior } \\
55 \text { Interior }\end{array}$ & $\begin{array}{l}70 \text { Exterior } \\
55 \text { Interior }\end{array}$ \\
\hline 3. & Mixed Area & NA & NA & 70 & 70 \\
\hline 4. & Commercial Area & 65 & 55 & 75 & 75 \\
\hline 5. & Industrial Area & 75 & 70 & 75 & 75 \\
\hline
\end{tabular}
metre. SEL is the sound exposure levels typical for a combination of light and heavy vehicles obtained using the sound level meter in the traffic stream.

Table 1: Different Standards of Noise Level for Various Areas of a Community

Source: [5]

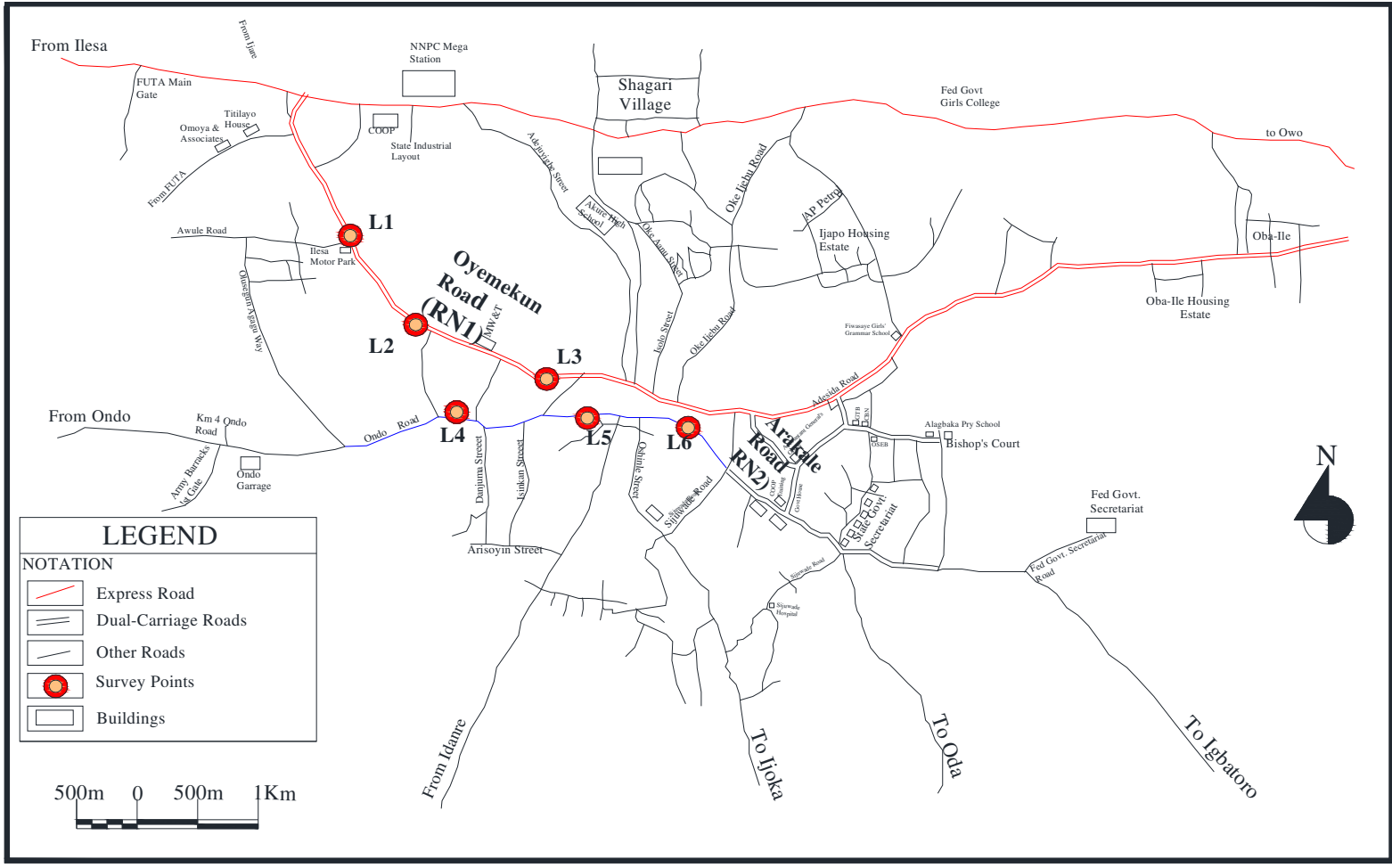

Figure 1: Road Networks Map of Akure Showing Survey Location Source: [11] 
Table 2: Percentage Evaluation of Passengers Car Unit

\begin{tabular}{|c|c|c|c|c|c|c|c|c|c|c|c|c|c|}
\hline \multirow{2}{*}{ Road } & \multirow{2}{*}{ Location } & \multirow{2}{*}{ Period } & \multicolumn{2}{|c|}{ Motorcycle } & \multicolumn{2}{|c|}{ Car/Taxi } & \multicolumn{2}{|c|}{ Mini Bus/Bus } & \multicolumn{2}{|c|}{2 Axle Load } & \multicolumn{2}{|c|}{3 Axle Load } & \multirow{2}{*}{$\begin{array}{c}\text { Total } \\
\text { PCU/hr }\end{array}$} \\
\hline & & & PCU & $\%$ & PCU & $\%$ & PCU & $\%$ & PCU & $\%$ & PCU & $\%$ & \\
\hline \multirow{6}{*}{ 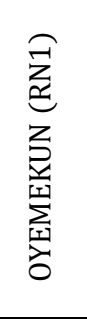 } & \multirow{2}{*}{ L1 } & Peak & 181.67 & 9.01 & 1532.83 & 76.74 & 263.00 & 13.15 & 14.00 & 0.69 & 8.00 & 0.41 & 1999.50 \\
\hline & & Offpeak & 171.00 & 9.36 & 1363.33 & 74.82 & 263.50 & 14.51 & 12.00 & 0.65 & 12.00 & 0.66 & 1821.83 \\
\hline & \multirow{2}{*}{ L2 } & Peak & 160.88 & 7.61 & 1527.50 & 72.08 & 408.50 & 19.10 & 16.67 & 0.78 & 9.00 & 0.43 & 2122.55 \\
\hline & & Offpeak & 151.00 & 7.44 & 1475.00 & 72.48 & 392.50 & 19.12 & 12.67 & 0.62 & 7.00 & 0.34 & 2038.17 \\
\hline & \multirow{2}{*}{ L3 } & Peak & 14.83 & 7.96 & 1281.67 & 71.23 & 332.67 & 18.38 & 21.33 & 1.21 & 21.50 & 1.22 & 1801.00 \\
\hline & & Off-Peak & 119.00 & 7.56 & 1075.00 & 67.65 & 345.00 & 21.87 & 27.33 & 1.73 & 19.00 & 1.19 & 1585.33 \\
\hline \multirow{6}{*}{ 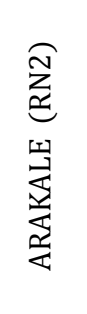 } & \multirow{2}{*}{ L4 } & Peak & 700.00 & 49.12 & 449.50 & 31.53 & 250.25 & 17.57 & 12.67 & 1.06 & 8.00 & 0.72 & 1428.58 \\
\hline & & Off-Peak & 622.17 & 47.62 & 424.33 & 32.45 & 244.50 & 18.55 & 10.00 & 0.76 & 8.00 & 0.62 & 1309.00 \\
\hline & \multirow{2}{*}{ L5 } & Peak & 715.42 & 47.62 & 459.17 & 32.23 & 272.75 & 18.47 & 14.00 & 0.99 & 9.00 & 0.69 & 1470.33 \\
\hline & & Off-Peak & 647.17 & 48.47 & 419.67 & 31.39 & 250.50 & 18.45 & 13.33 & 1.00 & 9.00 & 0.69 & 1339.67 \\
\hline & \multirow[b]{2}{*}{ L6 } & Peak & 590.67 & 46.64 & 454.17 & 35.59 & 195.92 & 15.32 & 18.67 & 1.46 & 13.00 & 0.99 & 1272.75 \\
\hline & & Off-Peak & 578.17 & 46.08 & 438.7 & 34.77 & 213.5 & 16.83 & 17.33 & 1.38 & 12 & 0.94 & 1259.67 \\
\hline
\end{tabular}

Note: L1 - Ilesha Garage, L2 - Adegbola, L3 - Oba Market, L4 -Isikan, L5 - Post Office Junction, and L6- Ecobank Junction.

Noise has always been an important environmental problem; however, noise associated with road development affects the environment through which roads pass by degrading human welfare, by sonically vibrating structures, and by disrupting wildlife. Traffic noise measurements and estimation can contribute significantly to the development of efficient methods of control.

The primary objectives of the study is to measure the average equivalent noise levels generated by the traffic circulating on the road network, estimate the noise level with regressive models and compare the measured values with the predicted ones.

Akure with the provisional census figure of 387,087 people according to 2006 national population census, is located on latitude $7020^{\prime \prime} \mathrm{N}$ and longitude $50 " \mathrm{E}$, while the natural pattern of development is linear along its main roads namely Oyemekun-Oba Adesida road and Arakale-Oda road. The existing land use is characterized by a medium density of structure within the inner core areas. Akure is made up of mainly of residential areas which make up $90 \%$ of the developed area but additional activities such as warehousing, manufacturing, workshops and other commercial uses are commonly located within the residential neighborhoods. At present the traffic composition of Akure is dominated by taxis, motorcycle (Okada) and minibuses.

\section{MATERIALS AND METHODS}

Noise measurements were done at a distance of $3 \mathrm{~m}$ from the road side of the nearest road band on the height of $130 \mathrm{~cm}$ above the road surface in accordance with BS 4142, 1997 using 407780A Integrating Sound Level Meter which conform with international electrotechnical commission (IEC) 61672. Measurements of traffic noise, spot speed and traffic volume variables were performed during the peak period (8:00am -9:00 am \& 4:00pm-5:00pm) and off peak period (12:00-1:00pm). The measurement was repeated 3-5 times to account for time-fluctuation of these variables, while keeping in view the traffic and population densities. The noise levels were recorded in decibel $(\mathrm{dB})$, while spot speeds and traffic volume count were recorded for all categories of vehicles using cine camera at six locations viz Ilesha Garage (L1), Adegbola (L2), Oba Market (L3), Isikan (L4), Post-office Junction (L5) and Eco Bank Junction (L6), the cine-camera was replayed to extract the data. Measurements were carried out every $15 \mathrm{~s}$ for a period of $15 \mathrm{~min} / \mathrm{h}$, this was considered to represent the variations in noise levels of the entire hour. Table 2 is the percentage evaluation of passenger's car unit, while Figure 1 is the road network map of Akure showing the selected sites.

\section{RESULTS AND DISCUSSIONS}

\subsection{Calculation of Equivalent Noise Level (LAeq)}

The equivalent noise levels (LAeq) at the selected locations were evaluated using equations (1), (3) and (4) respectively. Using Burgess model in equation (1), $L A e q=78.24 d B(A)$, Using British Standard-5228 Model in equation (3), and noting that $L_{W A}=$ $10 \log _{10}\left[\frac{P_{1}}{P_{0}}\right]^{2}=20 \log _{10}\left[\frac{P_{1}}{P_{0}}\right] ; \quad P_{1}$ is original sound 
pressure and $\mathrm{P}_{0}$ is magnitude of reference pressure $=$ $20 \mathrm{mPa}_{\mathrm{a}}$

$L_{A e q}=74.61 \mathrm{~dB}(A)$

Using FHWA Model in equation (4), we get:

$L A_{e q}=78.05 \mathrm{~dB}(\mathrm{~A}) \mathrm{dB}(\mathrm{A})$

Similarly, the average equivalent noise level during the peak and off-peak period were calculated in the same manner for other locations using three models, the summary is shown in Table 3. Also, Figure 2 and Figure 3 are the graph of the observed Sound Exposure Level versus the predicted Sound Exposure Level (LAeq) for the selected road network.

\section{CONCLUSION}

The average equivalent noise level on the road network in the study area using Burgess model, British standard model and FWHA model are $77.64 \mathrm{~dB}(\mathrm{~A})$, $72.95 \mathrm{~dB}(\mathrm{~A})$ and $75 \mathrm{~dB}(\mathrm{~A})$ respectively. The values obtained using Burgess and FWHA model were higher than $75 \mathrm{~dB}(\mathrm{~A})$ recommended by Policy on Traffic Noise Abatement 2011; while that obtained using British standard model is lower. However, the noise levels predicted by Burgess model and FWHA model also lies within an error band of $\pm 5 \%$ with reference to the observed noise levels. Thus, the three models are effective in predicting equivalent traffic noise index in Akure within a fair degree of accuracy. Also, 0.931 and 0.968 were obtained as the coefficient of correlation $\left(\mathrm{R}^{2}\right)$ for Oyemekun road (RN1) and Arakale road (RN2) when observed Sound Exposure Level was plotted against the predicted Sound Exposure Level (LAeq); thus, there is a good correlation between the observed and the predicted value. Road traffic noise can be reduced through adequate road design, management of traffic flow and the use of screens and barriers.

Table 3: Summary of Average Equivalent Noise Level

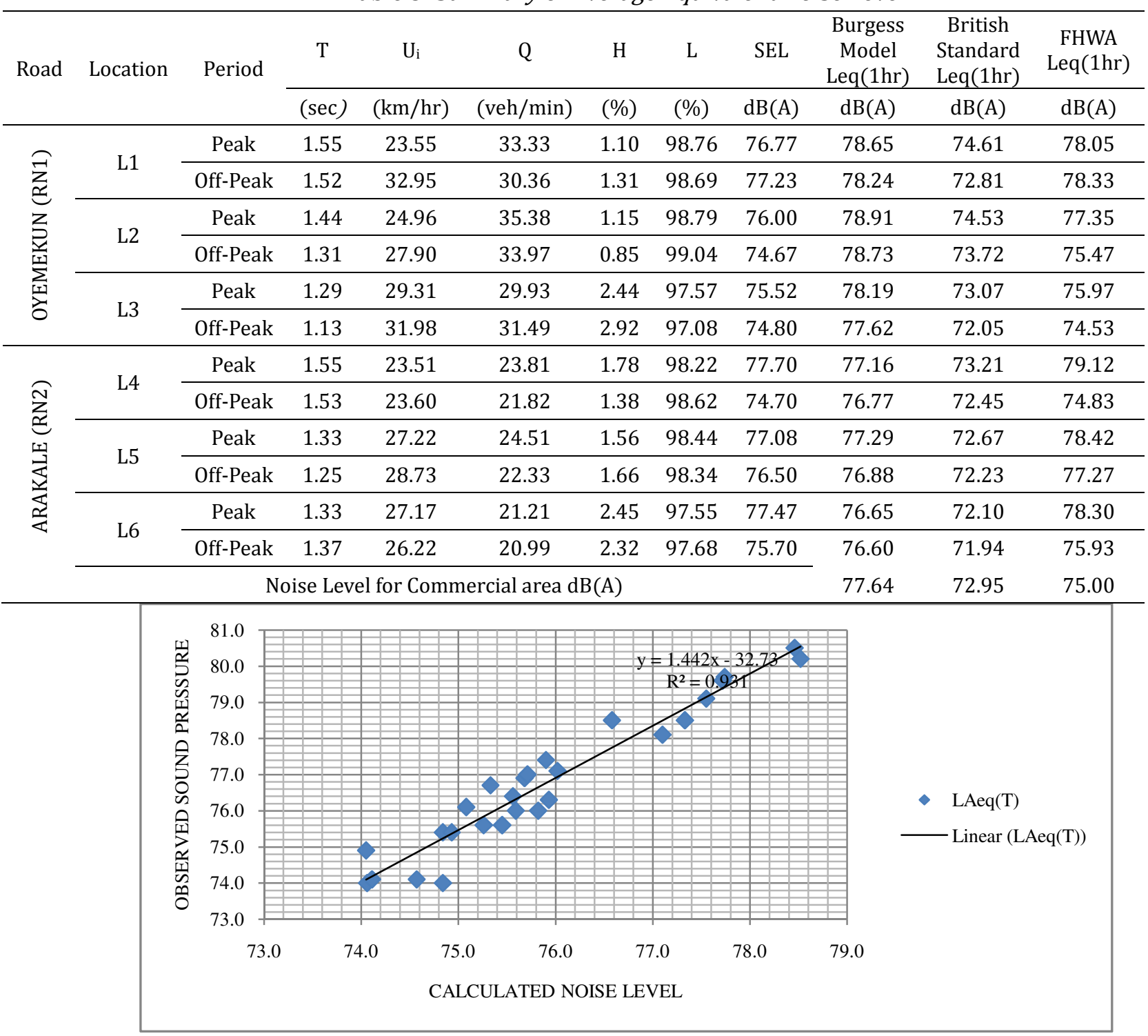

Figure 2: Observed Sound Exposure Level versus the Predicted Sound for RN1 


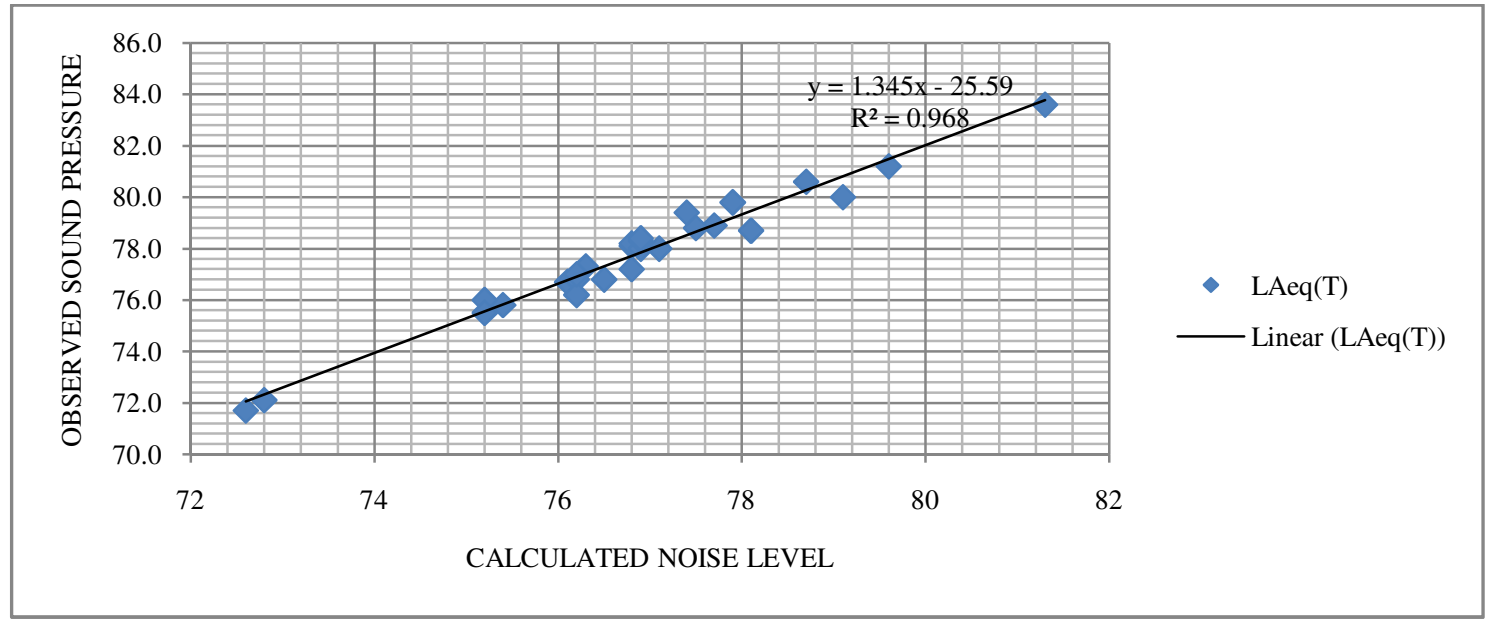

Figure 3: Observed Sound Exposure Level versus the Predicted Sound for RN2

\section{REFERENCES}

[1] Abbaspour, M., Golmohammadi, R., Nassiri, P., Mahjub, H., (2006). An Investigation on Time-Interval Optimization of Traffic Noise Measurement. Journal of Low Frequency Noise Vibration \& Active Control, Vol. 25 No. 4: 267-273.

[2] Acoustic Society of Japan (ASJ) Model (1998): Road Traffic Noise Prediction Model; Transportation Research Board Part 1

[3] Adie D.B., Otun J.A,Okuofu C.A. and Nasiru A. (2012): Assessment of Noise Generated By Operations Within The Gunduwawa Quarry In Kano State, Nigeria; Nigerian Journal of Technology Vol. 31, No. 3, pp. 314-320.

[4] W, Ising H, Gallacher J. E. J, Sweetnam P. M. and Elwood P. C. (1999).Traffic Noise and Cardiovascular Risk: The Caerphilly and Speedwell Studies, Third Phase-10-Year Follow Up; Archives of Environmental Health, Taylor \& Francis Vol. 54, No. 3, pp 210-216,

[5] BS 5228-1(2009): Code of Practice for Noise and Vibration Control on Construction and Open SitesPart 1:

[6] Burgess, M. A. (1977): Noise Prediction for Urban Traffic Conditions-Related to Measurements in the Sydney Metropolitan Area. Applied Acoustics, Vol. 10: 1-7.DOI: 10.1016/0003-682X (77)90002.

[7] Graham J. M. A, Janssen S. A, Vos H, and Miedema H. M. E (2009): Habitual Traffic Noise at Home Reduces Cardiac Parasympathetic Tone during Sleep. International Journal of Psychophysiology Vol. 72 No.2, pp. 179-186.
[8] Ljungberg JK and Neely G (2007): Stress, Subjective Experience and Cognitive Performance during Exposure to Noise and Vibration. Journal of Environmental Psychology Vol. 27 No.1, pp. 44-54.

[9] Mansouri, N.A., Pour Mahabadian, M., Ghasemkhani, M (2006). Road Traffic Noise in Downtown Area of Tehran, Iranian Journal of Environmental Health Science and Engineering, Vol. 3 No.4: 261-266.

[10] Ohrstrom E and Rylander R (1990). Sleep Disturbance by Road Traffic Noise-A Laboratory Study on Number of Noise Events; Journal of Sound and Vibration Vol. 143 No. 1, pp. 93-101.

[11] Ondo State Ministry of Land and Housing, 2010: Road Network Map of Akure

[12] Oyedepo O.J. Ekom R.I. and Ajala K.A (2013): Analysis of Traffic Noise along Oyemekun-Oba Adesida Road Akure Ondo State Nigeria; Journal of Engineering Science and Technology Review Greece Vol. 6 No.1, pp 72-77.

[13] Ross, M., Brain \& Wolde, T., (2001): Noise from Traffic as A Worldwide Policy Problem; Noise Control Engineering Journal, Vol. No.49 No.4, pp 159-161.

[14] Rylander R (2004): Physiological Aspects of NoiseInduced Stress and Annoyance. Journal of Sound and Vibration Vol. 277 No.3, pp. 471-478.

[15] Stefano, R. Danato, D. and Morri, B. (2001): A Statistical Model for Predicting Road Traffic Noise on Poisson Type Traffic Flow; Noise Control Engineering Journal, Vol.49 No. 3: 137-143.

[16] World Health Organization, (2005): United Nations Road Safety Collaboration: A Handbook of Partner Profiles, Geneva. 